\title{
Analysis of Shared Parking Lots Pattern
}

\author{
Yidan Li \\ School of Construction Management and Real Estate, Chongqing university, Chongqing400045, China.
}

1014258584@qq.com

Keywords: Shared parking lots, Parking management, Parking technologies.

\begin{abstract}
With increasing auto demands in China, the requirements for more parking lots and more efficient parking management rise with no doubt. However, how to take maximum advantages of current parking resources still remains to be discussed. A shared parking lots pattern is proposed in this paper, aiming to make full use of private parking lots. This parking lots pattern are based on advanced technologies widely used in human lives, of which problems and future development are also presented in this paper.
\end{abstract}

\section{Introduction}

Parking problems are chronic diseases for almost all large cities in China. Take Beijing for an example, according to the Beijing's statistical bulletin of the national economic and social development in 2014[1], the number of motorized vehicles reached 5.59 million, of which private vehicles occupied 78\%(4.37million), while the number of parking lots is only around 1.64 million. Obviously, even though the number of parking lots increases every year, it is far from totally meeting the parking demands. What's more, not all motorized vehicles have access to every parking place, which means that even if some parking lots in a private parking place are available for a period of time, they still cannot be made full use of because private parking places can only be used by their owners. Therefore, the unreasonable configuration of parking resources aggravated the lack of parking lots, making parking situations worse especially in downtown areas of big cities and also leading to results of higher parking fees and illegal car parking which certainly do harm to traffic management and urban environment.

The government has published laws and regulations to normalize the parking management. The three main regulations for parking in Chengdu are using Internet technology in parking information system, traffic restriction and punishment for illegal parking [2]. Internet technology in parking information system can help show people the exact way to available parking places and the accurate number of current available parking lots, etc. It has partly solved some traffic problems caused by parking information asymmetry and has provided people with convenience and guidance. However, as for the lack of parking lots and unreasonable resource allocation, the parking information system seems powerless. Traffic restriction may be a good idea to decrease the parking demands temporarily but it is not a sustainable way to settle the parking issues. When it comes to the punishment for illegal parking, apparently it has achieved some success in reducing illegal parking but actually it does not touch the key parking problem. In one word, all the three main regulations can definitely make parking process more convenient and figure out some traffic and parking troubles temporarily while the essential issue of parking resource redistribution still remains to be settled.

\section{The concept of shared parking lots pattern}

In this paper, the concept and development of a new method is proposed to help solving parking problems. The basic thought of the shared parking lots pattern is taking full advantage of private parking lots to provide more available parking lots in the real time and use technologies to optimize the parking process and parking experience. 
In the working hours, most people normally drive their cars to work places and thus leave their own parking lots unused. At the same time, plenty of people drive to crowded shopping malls and hospitals only to find that public parking places has been run out of. Obviously, if private parking lots can be available, parking problems will be solved for the most part.

To make the shared parking lots pattern come true, a specific parking process model is built, relying on advanced techniques. The descriptions of the model are presented as follows. To begin with, a shared parking lots application on the Internet is needed, which is a key platform for the connection and communication between owners of parking lots and people who need to park. After owners leave parking places, these parking places will be regarded as available for others to choose and positions of them can be seen on the application. Then people who need to park can choose the most suitable parking lots through the application and as soon as they enter the parking lots, the parking time will be counted on the application and money will be payed to owners according to the time.

\section{Analysis of techniques involved in the shared parking lots model}

According to the descriptions above, the shared parking lots pattern mainly based on 3 techniques: global positioning system(GPS), software technology and smart parking Technology.

The global positioning system, which is daily used by most people, is the basic technology in the parking pattern. When the owners of parking lots decide to take part in the parking system, the exact positions of their parking lots will be uploaded onto the parking app, which relies on the use of the global positioning system. Also, when a person chooses a parking lot on the app, the global positioning system will guide him/her to parking position. Besides, the data provided by GPS is the foundation for the parking app to match people who need to park with the most suitable and nearest parking lots. Thus, GPS is the basic technology for this shared parking pattern to act.

The software technology is also an essential part of the parking pattern infrastructure. The basic principle of the parking application is similar to that of Uber which has already offered us a fundamental application framework for us to refer to [3]. So It is necessary to analyze the Uber app first: In the beginning, both drivers and passengers register as users; For management and safety reasons, drivers have to fill in their real information including names, plate numbers, ID numbers and phone numbers, etc. As for passengers, they can bound their Alipay accounts to their Uber accounts so that the Uber app can directly deduct money they should pay from their Alipay accounts and fill in their phone numbers in order to contact drivers. When it comes to the shared parking application, owners of parking lots and people who need to park can be regarded respectively as "drivers" and "passengers" in the Uber pattern so that the owners of parking lots should upload real information like exact positions of parking lots, ID numbers and phone numbers, etc. On the other side, people who would like to park ought to fill in their plate numbers and phone numbers and can also link the parking accounts with online payment accounts. As for the match between owners and people who need to park and the process of parking, the software technology plays an important role in both parts. In Uber, right after passengers send requests of needs for drives on the app, the software technology will allow the app to analyze the position information of both passengers and drivers nearby based on the GPS information. Then several suitable drivers whose cars are available will be chosen by the application program and their positions and time that drivers need to get to the passengers' current positions will all be presented to passengers. According to passengers' needs and specific circumstances, passengers can choose one driver on their own and drivers will quickly pick them up. This process is similar to that of the shared parking pattern in which a person who need to park choose a parking lot based on the application analysis and then drive to the parking place with the guidance of the GPS.

When cars reach parking lots, the smart parking technology begins to work. Smart screens in the parking place is a part of the smart parking system to guide people to the chosen parking lots. Then with the authorization of owners, the users can use smart phones to link with the parking locks by WIFI networks or Bluetooth and unlocking parking locks means that the parking app starts to count 
the parking time. The last step of the parking pattern is to lock the parking locks and drive cars away and at the same time the app will stop counting time and money will be took off automatically from Alipay accounts. So the last parking part of how to park cars in chosen places and charge fares mainly depends on the smart parking system [4].

\section{Future development of the shared parking lots pattern}

Compared with the Uber pattern, there is no doubt that the two patterns have a lot in common. Despite the technologies mentioned above, the hypostasis of them is sharing economy which is a new developing economy pattern to integrate idle resources. On the other side, the differences between two patterns mainly embody in two aspects: the different type of resources and the different causes of problems which both patterns try to solve. Available cars, taxies and drivers are main resources required in the Uber pattern while private parking lots are needed in the shared parking lots. Cars and drivers are resources with mobility, which means that in Uber pattern, consumers are likely to get a drive even in remote places because if chosen drivers have the desire to pick consumers up, required resources (cars and drivers) are able to reach consumers' positions. While in the shared parking lots pattern, under possible circumstances when consumers are restrained by busy traffic or complex traffic conditions, there may be no available parking lots left or they are not able to reach chosen parking lots at all and the parking lots are certainly impossible to move. In addition, the duration for which parking lots are available is limited because only when owners themselves do not need to park in their communities their parking lots are available. So the shared parking lots may be less flexible and practical than the Uber pattern. As for the different causes of problems which both patterns try to solve, the problem Uber focuses on is asymmetry of time and space when people need a drive while the problem which the shared parking lots pattern is trying to solve is the inadequacy of parking lots resources and adding the private parking lots resources to the whole public parking system is one possible way to ease the severe parking problem. It is clear that though there are some differences between the Uber pattern and the shared parking lots pattern, they both try to use idle resources to solve serious problems and balance profits of different sides so the shared parking lots pattern can borrow a lot from the Uber pattern such as the design and operating process of the online application.

As we have mentioned above, global positioning system(GPS), software technology and smart parking technology are three basic technologies the shared parking lots pattern rely on. In the Uber pattern, the reliability of global positioning system and software technology has already been tested, which give us reasons to believe that the two technologies can still function well in the shared parking lots pattern. As for the smart parking technology, nowadays this technology has become mature and it has been widely used or starts to be extensively used in all over the world. In China, the government has published notifications in 2017 about setting examples of smart parking places in cities like Chengdu, Shenzhen, Beijing, etc. It shows that the smart parking system will soon or later be widely used in China and the government will certainly lay out more policies to encourage the use of the smart parking system [5]. Therefore, three essential technologies are reliable enough to support the feasibility of the shared parking lots pattern.

There are certainly shortcomings and faultiness in the shared parking lots pattern that we need to discuss. In China, the main problems are the coordination of people living in a community and the management of private parking places. The parking pattern may cause problems to property management companies which are responsible for the comfort and safety of people living in communities. Welcoming outsiders to park cars in private communities increases difficulties to investigate suspicious persons who might commit crimes, which may add the safety risks of residents. To solve safety problems, it is necessary to enforce the real-name system and identities of people entering communities must be checked by administrators. Besides, security people may be added and the security systems in communities and parking places must be upgrades, which will raise management costs of property management companies. Therefore, some residents and property management companies may fight against the shared parking lots pattern so how to balance profits of residents and property management companies is another problem waiting to be solved. The money 
paid by consumers may be divided by a reasonable proportion and given to interested parties, which definitely need an accurate measurement.

\section{Conclusion}

A shared parking lots pattern are presented in this paper, as with its technical support, comparisons with Uber pattern and problems it might have. There are possibilities for the shared parking lots pattern to come into reality, despite problems it faces like safety problems and benefit distribution difficulties. Generally speaking, the shared parking lots pattern is a reasonable theory to ease current parking problems and the technologies this pattern depends on are proved to be reliable enough. On the other side, many problems still exit in the pattern so we must have a precise calculation and balance interests of all parties before making the shared parking lots pattern come true.

\section{References}

[1] Beijing's statistical bulletin of the national economic and social development. (2014). Beijing, China. Beijing Statistics Office.

[2] Xu, C. W. The analysis of difficulty for parking in Chengdu and countermeasure research-As the view of government management[D]. Chengdu: Southwestern University of Finance and Economics Press. 2013. pp. 30-44.

[3] Zhou, L. X. Thoughts on the normalization of domestic car-hailing application markets- Based on the supervision experience of Uber business model in America[J]. Theory \& Practice.2015. (7).1-4.

[4] Song, C. The Design and Implementation of Phone Parking App System[D]. Jilin Province: Jilin University Press. 2016. pp.17-59.

[5] Notifications of setting examples and experimental units of urban parking places. (2017). Beijing, China. National Development and Reform Commission. 